\title{
Effect of Communication Competence Program on Nurses' Self-Advocacy
}

\author{
Nadia Mohamed Saleh ${ }^{1} \&$ Om Hashem Gomaa Ragab ${ }^{2}$ \\ 1. Assistant Professor of Nursing Administration Department, Faculty of Nursing, Sohag University, Eygpt \\ ${ }^{2 .}$ Lecturer of Nursing Administration, Faculty of Nursing, Sohag University, Egypt
}

\begin{abstract}
Background: Nurses may vary in communication skills as well as in their desire to really understand the patient, peers and others this could compromise the issue of advocacy. So it is important to improve nurses' communication competence to effective nurses' self-advocacy. Study aim to evaluate the effect of designed program of communication competence on nurses' self-advocacy. Research design: quasi experimental research design used. Subjects: No. $=(42)$ staff nurses. Setting; Sohag University Hospital Tool; consists of three parts; 1) personal characteristics; 2) Communication Competence Scale; and 3) Self-Advocacy Scale. Results: mean score of total communication competencies at pre intervention $(78.31 \pm 16.74)$, post $(112.67 \pm 10.61)$, and follow up $(106.17 \pm 9.7)$. Mean score of total self-advocacy at pre intervention (19.17 \pm 3.999$)$, post (30.26 \pm 3.85$)$, and follow up (25.81 \pm 3.4498$)$. Conclusion; there were positive correlation between communication competence and self-advocacy with highly statistical significant difference. Recommendations: implementation of communication training program in nursing education, assess communication competency among nurses periodically, and undergraduate nursing programs should contain communication competency course.
\end{abstract}

\section{Keywords: Communication, Competence, Nurses, Self-Advocacy \& Training program.}

\section{Introduction:}

The nursing profession in today's complex healthcare environment is extremely challenging. The scope of nursing practice defines that nurses protect patients, improve and optimize their health and capabilities, help prevent disease and injury, alleviate suffering, and cooperate in diagnostic and treatment plans, and this appears in advocacy in caring for individuals, families, communities and the entire population Salmond \& Echevarria, (2017).

Communication is a natural event, the field of communication focuses on how people use message to generate meanings within and across various contexts, cultures, channels, and media. Communication is an essential dimension of human life and of social spheres, such as health sphere, and concretely of therapeutic relations. The ability to effectively communicate with others is often included as a primary undergraduate learning goal along with other key skills like writing, critical thinking, and problem solving. Communication competence refers to the knowledge of effective and appropriate communication patterns and the ability to use and adapt that knowledge in various contexts or it is perceived tendency to seek out meaningful interaction with others Belim \& De Almeida, (2018).

There are multiple stages of competenc to assess as you communicate in your daily life: unconscious incompetence, conscious incompetence, conscious competence, and unconscious competence. Communication is important for our growth as human beings. It is part of our previous and everyday experiences. We are relational beings and this understanding makes us pursue further understanding about concepts, principles and abilities to be acquired in the communication process Hargie, (2017).

Dissonance between the high 'technical' professionalism of nurses and the relatively low level of patient satisfaction with care received is a phenomenon observed in many countries. Many studies show that it occurs in the case of an inadequate interpersonal communication between nurses and patients Szubzda \& Jarosz, (2012). The communication competence of nurses is essential to establish a therapeutic nurse-patient relationship. Education and strategic development are required to improve the communication competence Park et al., (2015).

Importance and prominence of nursing advocacy is reflected by its inclusion by various nursing bodies into their codes of ethics. Despite this opinion is polarized as to the nature and extent of nursing advocacy, the initial conception of nursing advovacy relatively modern idea, dating from the patient advocate movement of the 1970's. Nurses have reported "anger" and "frustration" as a result of having to advocate behalf of a patient. Research involving British nurses in senior positions has revealed beliefs that the practice is subject to paradoxes and contradictions and can cause interprofessional conflict within the health care system. The concept of advocacy as coming from the Latin "advocates", meaning one who is summoned to give evidence Davoodvand, et, al...( 2016). 
Successful advocacy depends on important messages being communicated and heard. However many nurses have a barriers to communication, so frequently they have few opportunities to influence decisions on the issues, policies and services that affect their lives self-advocacy and effective communication are an important part of the empowerment process for nurses https://www.ncbi.nlm.nih.gov/books/NBK310928/ (2021).

There are many national and international studies for effect of Communication Program. For examples in Egypt; Mahmoud \& Hassan (2018) in the study "Effectiveness of Communication Skills Training Program on Empathetic Skill and Communication Self Efficacy of Pediatric Oncology Nurses" were significant improvement in nurses' communication skills after implementing training. For international studies; Curtis et al., (2013) who assess the effects of a communication skills intervention for internal medicine and nurse practitioner trainees on patientand family, found that not significant changes in quality of communication. Bello \& Gray (2017) reported that, effective communication skills of healthcare provider were positive effect. Baer \& Weinstein, (2018) in the study titled "Improving Oncology Nurses' Communication Skills for Difficult Conversations," reported most participants felt improving their communication skills.

\section{Significance of the study:}

Nowadays training staff nurses to be competent for using communication skills more effective become a requirement that best fit with a dynamic workplace situations. During clinical training for nursing students at General Medical and Surgical departments the researchers observed some recurrent perplexing problem due to ineffective communication competence for nurses when deal with their patients and peers and they does not concern with selfadvocacy. This encourages the researchers to implement the program about communication competencies which help them to increase nurses' self-advocacy.

\section{The study aim:}

This study aims to evaluate the effect of designed program of communication competence on nurses' self-advocacy.

Research hypothesis:

There is a positive effect of communication competence program on nurses' self-advocacy.

\section{Subject and Method \\ Technical design \\ Research design \\ Quasi-experimental design used in the study.}

Setting

This study was impemented at General Medical and Surgical departments at Sohag University Hospital that provides health care services in Upper Egypt.

\section{Subjects}

Convenient sample; The total numbers were (42) staff nurses (23 General Medical and 19 Surgical Departments)

Tool of the study: It was consisted of three parts classified as follows:

First part: demographic data sheet, included items related to sex, age, years of experience, department she/he works in, social state, and past training programs about communication competences.

Second part: Communication Competences Scale which developed by Rubin \& Martin (1994), and adapted by the researchers. It consists of $\mathbf{3 0}$ items classified into ten factors related to communication competences for nurses'; Self-disclosure, (3items); Empathy (3items); Social relaxation (3items); Assertiveness (3items); Alter centrism (3items); Interaction management (3items); Expressiveness (3items); Supportiveness (3items); Immediacy (3items); and Environmental control (3items). The response to each item was on a five points Likert scale ranging from; ( $5=$ Almost always; $4=$ Often; $3=$ Sometimes; 2 = Seldom; and $1=$ Almost never). The tool includes negative statements number 5, 9, 11, 13, 20 , and 30 the reverse score considered for negative statements.

Scoring system of participant added up and distributed as follow: less than 90 low communication competences; from 90 - 119 moderate; and $\geq 119$ high, the tool total score was 150 . Scoring system for each sub-title considered as: $<9$ low; 9 - 11 moderate; and $\geq 12$ high, each sub-title total score was 15 .

Third part: Self-Advocacy Scale which developed by DeMarco \& Chan, (2013) and adapted by the researchers. It consists of $\mathbf{9}$ items to determine selfadvocacy for nurses'. The responses of five point Likert scale ranged from (5) strongly agree, (4) agree, (3) are neutral or undecided, (2) disagree, or (1) strongly disagree. The tool includes negative statements number 9 the reverse score considered for it. Scoring system participant will be added up and distributed as follow: below 60\% low self-advocacy; and $60 \%$ or more high self-advocacy. The tool total score was 45 .

\section{Administrative Design}

An official permission was obtained from the General Director and Nurse Director of Sohag University Hospital.

Operational design:

Preparatory Phase.

It took about three months from June to August (2019) to review the available literatures concerning 
to the study topic, prepares, and translates the tools. The draft of the questionnaire was reviewed for face validity by taking experts opinions through a jury comprised by five experts from Faculty of Nursing Assiut University, and accordingly the necessary modification was done.

Design the program: includes: aim and objectives of the program, concept of communication, definition, and importance of communication, types, and elements of communication competences, barriers of effective communication.

Implementing activities; types and elements of communication competence; barriers of effective communication and techniques to deal with it.

\section{Pilot Study:}

It was done to explore any obstacles or problems that may be encountered during data collection phase. It helps also in estimating time needed to fill in the questionnaire form. It was carried out on $10 \%$ of staff nurses; the total period for collection of data in the pilot study takes about 6 days. The participants chosen for the pilot study were excluded from the total study sample.

Reliability was measured using Cronbach's Alpha Coefficients methods to ensure internal consistency and its result revealed that all statements of study questionnaire $\alpha$ were $>0.85$ for communication competence questionnaire, and $>0.89$ for selfadvocacy questionnaire.

Filed Work: implementation of the program: the researchers collected the data by using the questionnaire sheets of communication competences and self-advocacy which filled in by staff nurses before starting the program as (pretest), then immediately post implementation and 3 months after the program. Each staff nurse needed from $10-15$ minutes to complete each sheet. The program was implemented four times, to four groups of staff nurses according to the working place of each group. The total time allocated for achieving the whole program to each group was 12 hours through two days (3 session's $\times 2$ hours for every day), one group per week. Each group was (10-11) staff nurse

Teaching and learning methods used includes; work in small groups, group discussion, interactive lectures, brain storming, and demonstration.

The program started at the beginning of September 2019 and finished at the beginning of October 2019.

Follow up phase started from beginning of December 2019 with the first group who received the program was at September 2019 to the end of January 2020 with the last group who received the program at October 2019. The researchers contacted with them at their work place.

\section{Ethical considerations:}

The research proposal approval was taken from ethical committee at Faculty of Nursing Sohag University. Then oral agreement was taken from all participants after explained the purposes of the study and informing them about their rights to participate, refuse, or withdraw at any time. Total confidentiality of any obtained information was ensured. The steps of the study could not entail any harmful effect on participants.

\section{Statistical Analysis:}

The entry of data and statistical analysis were done using Statistical Package for Social Sciences (SPSS) 26.0 software. Data presented in the form of frequencies, percentages, means and standard deviations. Relation differences calculated for frequency variables using chi square test while means compared using F-test through One Way ANOVA. Correlation calculated using Pearson correlation analysis of the inter-relationships among variables. Statistical significance was considered at $\mathrm{p}$-value $<0.05$ and highly significance at $\mathrm{P}<0.001$. 


\section{Results:}

Table (1): Percentage distribution of the studied nurses according to their characteristics $(n=42)$.

\begin{tabular}{|l|c|c|}
\hline Personal characteristics & No. & \% \\
\hline Age/(years): & 2 & 4.8 \\
\hline$-<25$ & 9 & 21.4 \\
\hline$-25-<30$ & 20 & $\mathbf{4 7 . 6}$ \\
\hline$-30-<35$ & 11 & 26.2 \\
\hline$-\geq 35$ & \multicolumn{2}{|c|}{$32.02 \pm 4.45$} \\
\hline Mean \pm Std. Deviation & \multicolumn{2}{|c|}{} \\
\hline Experience/(years): & 1 & 2.4 \\
\hline$-<5$ & 4 & 9.5 \\
\hline$-5-<10$ & 9 & 21.4 \\
\hline$-10-<15$ & 21 & $\mathbf{5 0 . 0}$ \\
\hline$-15-<20$ & 7 & 16.7 \\
\hline$-\geq 20$ & \multicolumn{2}{|c|}{$14.74 \pm 4.64$} \\
\hline Mean \pm Std. Deviation & 23 & \\
\hline Unit & 19 & $\mathbf{5 4 . 8}$ \\
\hline- Medical & \multicolumn{2}{|c|}{} \\
\hline- Surgical & 40 & 45.2 \\
\hline Social status & 2 & $\mathbf{9 5 . 2}$ \\
\hline- Married & \multicolumn{2}{|c|}{} \\
\hline- Unmarried & 34 & $\mathbf{8 1 . 0}$ \\
\hline Qualification & 7 & 16.7 \\
\hline- Secondary school of nursing Diploma & 2.4 \\
\hline- Clinical institute of nursing & 1 & \\
\hline- Bachelor of nursing & \multicolumn{2}{|}{} \\
\hline $\begin{array}{l}\text { Attending previous training program about } \\
\text { communication competences }\end{array}$ & 4 & $\mathbf{9 0 . 5 \%}$ \\
\hline- Yes & 38 & \\
\hline- No & \multicolumn{2}{|c|}{} \\
\hline
\end{tabular}

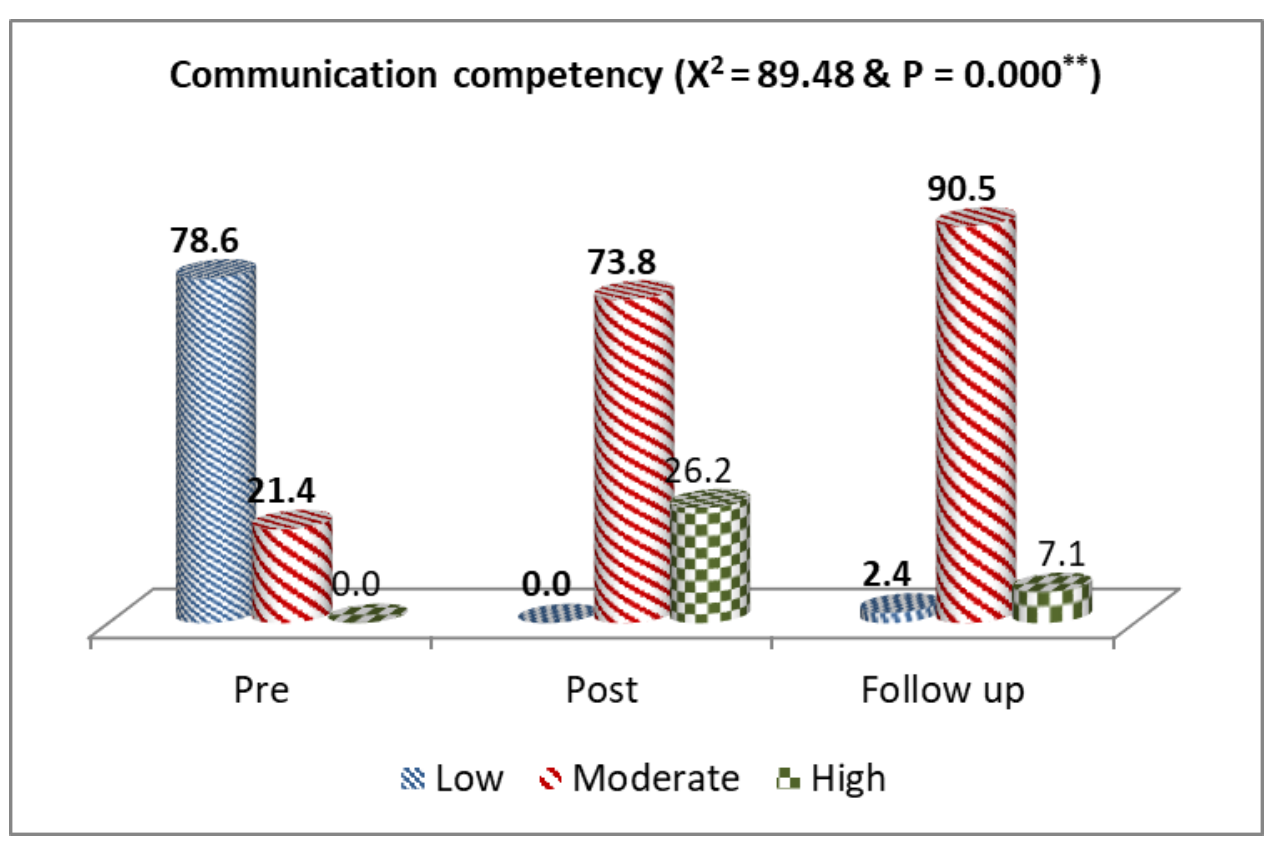

Figure (1): Percentage distribution of studied nurses' communication competencies in relation to pre, post study and follow-up $(n=42)$. 


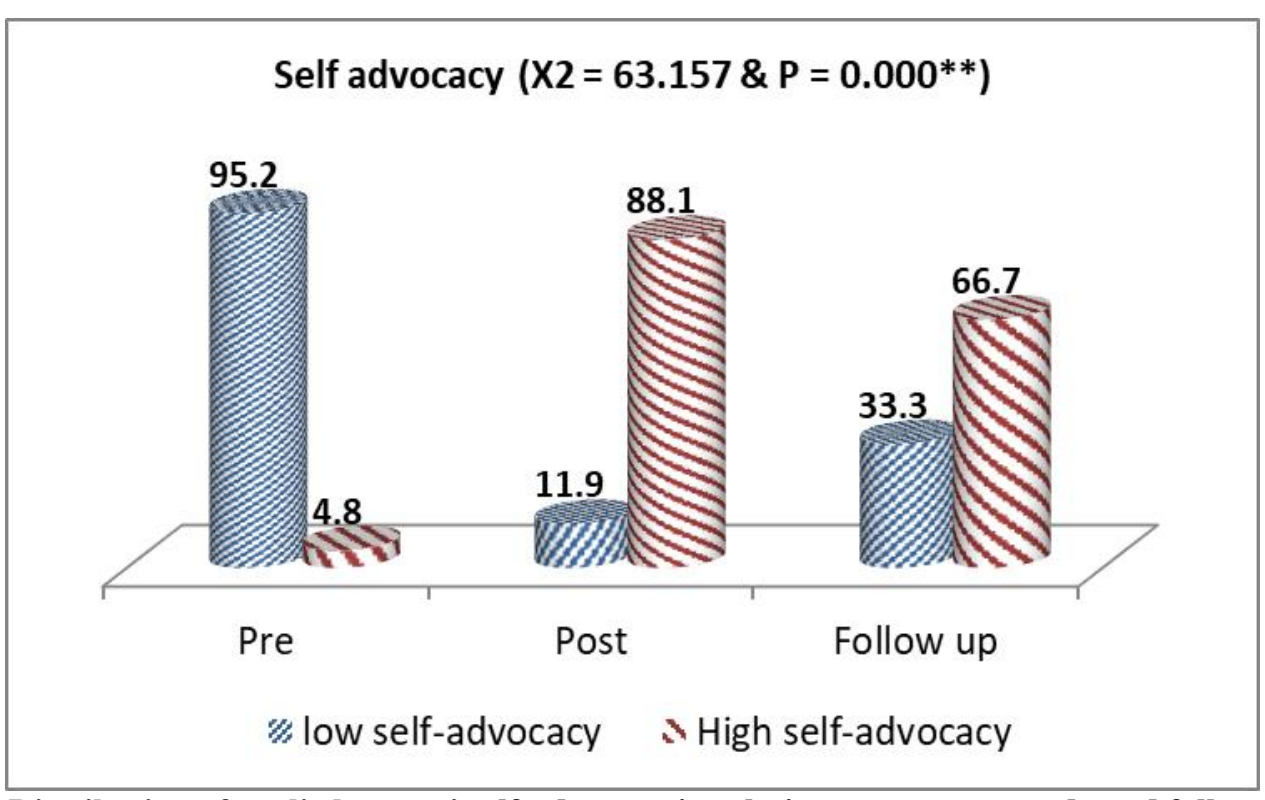

Figure (2): Distribution of studied nurses' self-advocacy in relation to pre, post study and follow-up (n=42).

Table (2): Mean score of communication competencies between studied nurses throughout the program $(n=42)$.

\begin{tabular}{|l|c|c|c|c|c|c|}
\hline \multicolumn{1}{|c|}{ Items } & Total & Pre & Post & Follow up & \multirow{2}{*}{ F } & P - \\
\cline { 3 - 6 } & Score & Mean \pm SD. & Mean \pm SD. & Mean \pm SD. & \\
\hline Self-disclosure & 15 & $8.12 \pm 2.41$ & $11.07 \pm 2.31$ & $9.69 \pm 2.77$ & 14.599 & $0.000^{* *}$ \\
\hline Empathy & 15 & $7.26 \pm 2.33$ & $11.595 \pm 1.82$ & $10.41 \pm 1.91$ & 50.536 & $0.000^{* *}$ \\
\hline Social relaxation & 15 & $7.62 \pm 2.46$ & $11.10 \pm 2.49$ & $10.45 \pm 2.29$ & 24.684 & $0.000^{* *}$ \\
\hline Assertiveness & 15 & $8.29 \pm 2.31$ & $11.07 \pm 2.16$ & $10.90 \pm 2.195$ & 20.777 & $0.000^{* *}$ \\
\hline Alter centrism & 15 & $7.79 \pm 2.06$ & $11.33 \pm 1.97$ & $11.21 \pm 1.95$ & 43.017 & $0.000^{* *}$ \\
\hline Interaction management & 15 & $7.98 \pm 2.05$ & $11.38 \pm 2.05$ & $11.00 \pm 2.08$ & 34.384 & $0.000^{* *}$ \\
\hline Expressiveness & 15 & $7.57 \pm 2.41$ & $10.93 \pm 2.13$ & $10.74 \pm 2.096$ & 30.352 & $0.000^{* *}$ \\
\hline Supportiveness & 15 & $7.71 \pm 3.06$ & $11.29 \pm 2.028$ & $10.21 \pm 2.45$ & 21.738 & $0.000^{* *}$ \\
\hline Immediacy & 15 & $8.00 \pm 2.96$ & $11.93 \pm 2.24$ & $11.29 \pm 2.09$ & 30.859 & $0.000^{* *}$ \\
\hline Environmental control & 15 & $7.98 \pm 2.82$ & $10.98 \pm 2.63$ & $10.26 \pm 1.99$ & 16.432 & $0.000^{* *}$ \\
\hline Total of communication competencies & 150 & $78.31 \pm 16.74$ & $112.67 \pm 10.61$ & $106.17 \pm 9.79$ & 85.854 & $0.000^{* *}$ \\
\hline
\end{tabular}

**Highly significant $P<0.001$

Table (3): Mean score of studied nurses at pre, post, follow up intervention related to total selfadvocacy $(n=42)$.

\begin{tabular}{|c|c|c|c|c|c|c|}
\hline \multirow{2}{*}{ Item } & Total & Pre & Post & Follow up & \multirow{2}{*}{ F } & \multirow{2}{*}{ P - Value } \\
\cline { 3 - 5 } & Score & Mean \pm SD. & Mean \pm SD. & Mean \pm SD. & & \\
\hline Self-Advocacy & 45 & $19.17 \pm 3.999$ & $30.26 \pm 3.85$ & $25.81 \pm 3.44$ & 92.22 & $0.000^{* *}$ \\
\hline
\end{tabular}

**Highly significant $P<0.001$

Table (4): Correlation between studied variables at post intervention

\begin{tabular}{|l|l|l|}
\hline & \multicolumn{2}{|c|}{ Communication competencies } \\
\hline \multirow{2}{*}{ Self-advocacy } & r. & 0.342 \\
\cline { 2 - 3 } & $\mathbf{P}$ - Value & $0.000^{* *}$ \\
\hline
\end{tabular}

**Highly significant $P<0.001$ 
Table (1): Revealed that mean age of studied nurses was $(32.02 \pm 4.45)$, most of them $(95.2 \%)$ were married, about $(81.0 \%)$ of them had Secondary school of nursing Diploma qualification. Also, this table shows means score of nurses experiences was $(14.74 \pm 4.64)$, and about $(90.5 \%)$ of them did not attended previous training program about communication competences.

Figure (1) Illustrates that the highest percentage of the study sample $78.6 \%$ has low communication competencies pre study, $73.8 \%$ and $90.5 \%$ has moderate competencies as regard to post and follow up respectively. There was high statistically significant differences $\left(\mathrm{X}^{2}=89.48 \& \mathrm{P}=0.000^{* *}\right)$.

Figure (2): Depicts that the most of the study sample $(95.2 \%)$ has low self-advocacy pre study, while the highest percentage regarding study sample has high self-advocacy (88.1\% and $66.7 \%$ ) post and follow up of the study respectively. There was highly statistical significant differences $\left(\mathrm{X}^{2}=63.157 \& \mathrm{P}=0.000^{\text {*** }}\right)$.

Table (2): Displays that, highest means scores were post intervention of the program and there were high significant differences between studied nurses at pre, post and follow up intervention related to all communication competencies dimensions $\mathrm{P}<0.001$.

Table (3): Shows that mean score of total selfadvocacy at pre intervention was (19.17 \pm 3.999$)$, post intervention was $(30.26 \pm 3.85)$, and follow up was $(25.81 \pm 3.44)$. There was highly statistical significant difference $\mathrm{P}<0.001$.

Table (4): Shows there was positive correlation between communication competencies and selfadvocacy with highly statistical significant differences ( $\left.\mathrm{r} .=0.342 \& \mathrm{P}=0.000^{* *}\right)$.

\section{Discussion:}

Communication considered an important and integral part of life, and without communication no one can live. Both verbal and non-verbal communication with a person begins at birth and does not end until death Vertino, (2014). Communication between health care providers and patients affects patient care, safety, and outcomes. Nurses develop communication skills during education, after graduation and throughout their practice. Improving communication among health care providers has been identified as part of the 2015 National Safety Goals. Without adequate communication skills to address concerns, advocacy is threatened. Advocacy is an essential component of nursing practice, Advocacy implies taking action to achieve a goal, either on behalf of oneself or on behalf of another. The code of practice for nursing identifies the responsibility for advocacy The Joint Commission (2015).

This study was conducted with the aim to evaluate the effect of a designed program of communication competence on nurses' self-advocacy. The present study depicts that, slightly less than half of the participants aged from 30 to less than 35 year old, the majority of them were married, and have diploma of nursing school, half of them their experience from 15 to less than 20 years, and most of them reported no previous training program attended about communication competence.

The present study indicated that highest percentage of the study sample was low communication competencies pre intervention, meanwhile moderate competencies as regard to post and follow up and there was highly statistical significant difference. This result supported with Bello \& Gray, (2017) in his study titled "Effective Communication in Nursing Practice" indicates that the use of effective communication skill in healthcare settings does not only benefit patients it also benefits healthcare providers. Also agreement with Baer \& Weinstein, (2018) they reported that most participants felt improving their communication skills, as evidenced by post-survey scores. This result may be related to most of staff before program has difficult to communicate effectively with their patient and peers but after the program learn more communication competences which help them to improve their skills in the work place.

The result of present study revealed that most of the study sample were low self-advocacy pre intervention, while the highest percentage regarding study sample were high self-advocacy post and follow up of the study and there was highly statistical significant difference. This result supported with Doherty et al., (2016) in the study titled; Impact of Communication Competency Training on Nursing Students' Self-advocacy Skills, measures non-selfadvocating beliefs and behaviors so a decrease in score represents an improvement in self-advocacy behaviors and there was a statistically significant difference. This result may be related to most of staff after the program they known communication competences which help them to improve their selfadvocacy.

Current study result displays that there was high statistical significant differences between studied nurses at pre, post and follow up intervention related all communication competencies dimensions, and the highest means scores were post intervention of the program. This result supported with Mahmoud \& Hassan (2018) they showed that, there was significant improvement in communication and empathetic skills for nurses' after implementing the training. And also agreed with Khodadadi et al., (2013) they found that, there were significant differences in nurse's quality of communication skills after intervention. Meanwhile this result disagreed 
with Curtis et al., (2013) they reported that; there were no significant changes in quality of communication with intervention. And also disagreed with Reyhani et al., (2015), they found that, no significant differences in verbal and nonverbal communication after intervention.

This result may be related to the effective of the program which leads to increase the awareness of staff nurses about communication competencies and how they can improve their communications skills.

The study results demonstrate that the highest mean score of total self-advocacy was post intervention of the program. There was highly statistical significant difference. This result supported with Sheldon \& Hilaire (2015) in the study; "Development of communication skills in healthcare: Perspectives of new graduates of undergraduate nursing education" reported that, Participants reported always feeling confident communicating with patients and families, and with interdisciplinary teams. Only half of them reported always feeling confident to provide safe care all of the time with feeling always able to ask colleagues for help with challenging situations. This result may be related to the effective of the program to improve self-advocacy.

The study result shows that, there was a positive correlation between communication competencies and self-advocacy with highly statistical significant differences. This result supported with Doherty et al., (2016) reported that providing communication competency education to nursing students positively impacts the students' ability to advocate for themselves and their patients and should influence their delivery of health care and agreement with Bello \& Gray (2017) reported that effective communication skills of healthcare provider has positive effect on the recovery rate of patient's health status, and poor communication skills could negatively impact the health status of patient. This result may be related to the positive effect of designed program of communication competences on nurses' self-advocacy.

\section{Conclusion}

1. The current study concluded that the highest percentage of the study sample were low communication competencies pre intervention, and moderate competencies at post and follow up.

2. The most of the study sample has low selfadvocacy pre intervention, while they were high self-advocacy post and follow up.

3. There were high statistical significant differences between studied nurses at pre, post and follow up related all communication competence dimensions.
4. The mean score of total communication competencies and self-advocacy at post intervention was highest than pre intervention.

5. There was positive correlation between communication competencies and self-advocacy with highly statistical significant differences

\section{Recommendations}

1- Implement in-service education for nurses because they have very busy schedule in majority of healthcare settings, they become less aware of the problem of ineffective professional communication style.

2- Implementation of communication competence as a separate course in nursing education.

3- Developing standard to periodically assess communication competency among nursing staff.

4- Undergraduate nursing programs should contain communication competency course.

5- Nurse Manager should be scheduled regular meetings with the nursing staff to help them to solve the communication current problems which arise at work place.

\section{References}

- Baer, L., \& Weinstein, E., (2018): Improving Oncology Nurses' Communication Skills for Difficult Conversations. Oncology Nursing Society. Unauthorized reproduction, in part or in whole, is strictly prohibited.. Clinical Journal of Oncology Nursing $\bullet$ Volume 17, Number 3.

- Belim C, De Almeida CV (2018): Communication Competences are the Key! A Model of Communication for the Health Professional to Optimize the Health Literacy - Assertiveness, Clear Language and Positivity. Journal of Healthcare Communication, Vol. (3), No. (3:31), Pp. 1-13.

- Bello O., \& Gray P., (2017): Effective Communication in Nursing Practice: A literature review. Bachelor's Thesis Degree Programme in Nursing.

- Curtis, R, Back, L., Downey, L., Shannon, E., Doorenbos, Z., Kross, K., Feemster, C. \& Connor., O. (2013): Effect of communication Skills Training for Residents and Nurse Practitioners on Quality of Communication With Patients With Serious Illness. A Randomized Trial. JAMA December 4, Volume 310, Number 21

- DeMarco, R., \& Chan, K. (2013): The Sistah Powah structured writing intervention: A feasibility study for aging, low-income, HIV-positive black women. American Journal of Health Promotion; Jack, D., Dill, D. The Silencing the Self Scale: Schemas of Intimacy Associated With Depression in Women Psychology of Women Quarterly, 16 (1992), 97-106. 
- Doherty, S., Landry, H., \& Pate, B., \& Reid H. (2016): Impact of Communication Competency Training on Nursing Students' Self-advocacy Skills. Nurse Educator, Vol. 41, No. 5, pp. 252-255 Copyright * 2016 Wolters Kluwer Health, Inc. All rights reserved

- Hargie O., (2017): Skilled Interpersonal Communication

Research, Theory and Practice, $6^{\text {th }}$ Edition. ISBN 9781138823778. Published September 29, 2016 by Routledge.chapter $1 \quad$ p.p 1-38. https://www.ncbi.nlm.nih.gov/books/NBK310928/ 29 march 2021 at $10 \mathrm{pm}$

- Khodadadi, E. Ebrahimi, H. Moghaddasian, S. \& Babapour, J. (2013): The Effect of Communication Skills Training on Quality of Care, Self-Efficacy, Job Satisfaction and Communication Skills Rate of Nurses in Hospitals of Tabriz, Iran. Journal of Caring Sciences, 2(1), 32

- Davoodvand, S, Abbaszadeh, A, \& Ahmadi, F. (2016): Patient advocacy from the clinical nurses' viewpoint: a qualitative study. J Med Ethics Hist Med 2016; 9: 5.

- Mahmoud S., \& Hassan M., (2018): Effectiveness of Communication Skills Training Program on Empathetic Skill and Communication Self Efficacy of Pediatric Oncology Nurses. IOSR Journal of Nursing and Health Science (IOSRJNHS) e- ISSN: 2320-1959.p- ISSN: 2320-1940 Volume 7, Issue 2 Ver. 1 (March .2018), PP 75-85.

- Park MS, Jeoung Y, Lee HK, \& Sok SR. (2015): Relationships among communication competence, self-efficacy, and job satisfaction in Korean nurses working in the emergency medical center setting. J Nurs Res. Jun; 23(2):101-8. doi: 10.1097/JNR.0000000000000059.

- Reyhani, T. Razi, M., Mohsen., S. Nekah, A. \& Yavari,M. (2015): The Effect of Training on Communication Skills of Child's Nurse through Role- playing. International journal pediatrics .Vol.3, N.5-2, Serial No.22.

- Rubin R., \& Martin M., (1994): Development of a measure of interpersonal communication competence, communication research reports, volume (11) number (1) pages 33-44. https://www.researchgate.net/puplication/2383187 22 All content following this page was uploaded by Martin on 02 May 2016

- Salmond, S. \& Echevarria, M. (2017): Healthcare Transformation and Changing Roles for Nursing. Orthopaedic Nursing; Vol. (36), No. (1), Pp. 12-25.

- Sheldon L., \& Hilaire D., (2015): Development of communication skills in healthcare: Perspectives of new graduates of undergraduate nursing education". Journal of Nursing Education and Practice Vol. 5, No. 7

- Szubzda W. \& Jarosz J. (2012): Professional communication competences of nurses. Ann Agric Environ Med. 2012;19(3):601-607

- The Joint Commission (2015): Hospital National Patient Safety Goals. 2015. Available from: http://www.jointcommission.org/assets/1 /6/2015_hap_npsg_er.pdf

- Vertino, K. (2014): Effective Interpersonal Communication: A practical Guide to Improve Your Life. OJIN: The Online Journal of Issues in Nursing Vol. 19. 2014 Sep 30; 19(3):1. 